\title{
PENINGKATAN KETERAMPILAN PENGGUNAAN APLIKASI KAHOOT BAGI GURU DI SMA NEGERI 11 PALEMBANG
}

\author{
Yunika Lestaria Ningsih ${ }^{1}$, Nila Kesumawati ${ }^{2}$, Putri Fitriasari ${ }^{3}$, Dina Octaria ${ }^{4}$, Allen Marga \\ Retta $^{5}$, Tika Dwi Nopriyanti ${ }^{6}$ \\ 1,2,3,4,5,6Program Studi Pendidikan Matematika, Fakultas Keguruan dan Ilmu Pendidikan \\ Universitas PGRI Palembang \\ Email: yunikalestari@univpgri-palembang.ac.id
}

\begin{abstract}
Nowadays, digital information resources are available and can be accessed easily by educators and learners. References for studying both material and evaluation instruments can also be found e asily by using the search engine. One application thatcan be used by teachers in making digital learning evaluation instruments is the Kahoot! Application. The objectives of this activity are: (1) to introduce the Kahoot! as a learning medium, especially in making online quizzes, and (2) to improve teacher skills in using the Kahoot! application. The implementation method used in this activity is lectures, practice, and discussion. Data were collected through a training satisfaction questionnaire. The results showed that the training was runvery well, and the participants were very enthusiastic. The data analy sis showed that $91.38 \%$ of participants stated that this training activity could increase teachers' $k$ no wle dge about the Kahoot! in learning, and $90.52 \%$ of participants stated that this training could improve teacher skills in using the Kahoot! application.
\end{abstract}

Keywords: Kahoot! application, online quizzes, evaluation instrument

\begin{abstract}
Abstrak. Pada era big data sekarang ini, sumber dayainformasi digital telah tersedia dan dapat dia kses den ga m mudah oleh para pendidik dan pembelajar. Referensi untuk belajar baik itu materi dan instrumen eva luasi juga dapat ditemukan dengan mudah dengan menggunakan mesin pencarian Google. Sa lah sa tu a plika si y ang dapat dimanfaatkan oleh guru a tau tenaga pengajar lainnya dalam m embuat in strumen evaluasi pembelajaran digital adalah aplikasi Kahoot!. Tujuan kegiatan ini adalah : (1) untuk mengenalkan aplikasi Kahoot! sebagai media pembelajaran khususnyadalam membuat kuis onlin e, d an (2) untuk meningkatkan keterampilan guru dalam menggunakan aplikasi Kahoot!. Metode pe laksa naan yang digunakan dalam kegiatan iniadalah ceramah, praktik dan diskusi. Da ta dikumpulkan melalui angket kepuasan pelatihan. Hasil pelaksanaan kegiatan menunjukkan bahwa kegiatan pela tihan berjalan denga n la ncar, dan peserta kegia tan a ntusias dalam mengikuti pelatihan. Da ri hasil a nalisis da ta d a pat disimpulkan bahwa 91,38\% peserta kegiatan menyatakan bahwa kegia tan pelatihan ini da pat me na mbah pengetahuan guru tentang a plikasi Kahoot! dalam pembelajaran, dan 90,52\% peserta menyatakan ba hwa pelatihan ini dapat meningkatkan keterampilan guru dalammenggunakan aplikasi Kahoot!.
\end{abstract}

Kata Kunci: aplikasi Kahoot!, kuis online, instrumen evaluasi

\section{PENDAHULUAN}

Pada era big data sekarang ini, sumber daya informasi digital telah tersedia dan dapat diakses dengan mudah oleh para pendidik dan pembelajar. Referensi untuk belajar baik itu materi dan instrumen evaluasi juga dapat ditemukan dengan mudah dengan menggunakan mesin pencarian Google. Oleh karena itu, kemampuan literasi digital mutlak diperlukan bagi guru sebagai pendidik agar informasi yang tersedia dapat diolah dan dimanfaatkan dengan maksimal (Kurnianingsih, Rosini, and Ismayati 2017)

Literasi digital dijelaskan oleh Martin (Chan et al., 2017) yaitu kemampuan seseorang dalam mengidentifikasi, mengakses, memanajer, mengintegrasikan, mengevaluasi, menganalisis dan menyintesis sumber informasi digital. Selain itu, literasi digital juga dapat diartikan sebagai kemampuan seseorang dalam membaca, menulis, menyaksikan, mendengarkan, membuat, dan mengkomunikasikan suatu informasi (Lankshear \& Knobel, 2008).

Perlunya memiliki kemampuan literasi digital ini, dituangkan oleh pemerintah dalam Permendikbud No 69 tahun 2013 tentang kurikulum SMA-MA yang mengharuskan penggunaan teknologi informasi dalam proses pembelajaran (Arifin \& Hala, 2019). Salah satu aplikasi yang dapat dimanfaatkan oleh guru atau tenaga pengajar lainnya dalam membuat instrumen evaluasi pembelajaran digital adalah aplikasi Kahoot!. Menurut Singer (Heni et al., 2017). Kahoot! adalah suatu alat yang dapat 
digunakan untuk menyampaikan atau mempresentasikan pertanyaan ke siswa. Pertanyaan tersebut diseting dalam sebuah permainan dan dapat dimainkan oleh siswa baik secara individu maupun berkelompok melalui smartphone ataupun laptop. Kahoot! adalah suatu platform pembelajaran berbasis permainan yang dapat digunakan untuk meriviu pengetahuan siswa, untuk penilaian formatif yang bentuknya berbeda dari pembelajaran tradisional (Wang \& Tahir, 2020). Lebih lanjut menurut Siegel (Wibisono, 2019) aplikasi ini merupakan platform yang dapat digunakan secara gratis dan dapat digunakan sebagai media dalam membuat kuis lengkap dengan gambar dan video.

Aplikasi kuis online ini diidentifikasi bermanfaat dalam proses pembelajaran karena memiliki potensi dalam merangsang motivasi belajar siswa dengan adanya feedback dan strategi layaknya sebuah permainan (Licorish et al., 2018). Beberapa penelitian terdahulu menunjukkan bahwa aplikasi Kahoot! mempunyai dampak positif dalam pembelajaran. Aplikasi ini dapat membuat pembelajaran menjadi lebih efektif (Putri \& Muzakki, 2019; Wibisono, 2019). Selain itu, penggunaan aplikasi ini juga dapat meningkatkan keaktifan siswa dalam pembelajaran (Heni et al., 2017).

Namun dibalik berbagai manfaat yang dapat diperoleh dari aplikasi Kahoot!, masih banyak guru atau tenaga pendidik yang belum mengetahui dan belum bisa menggunakannya dalam proses pembelajaran. Berdasarkan wawancara awal yang dilakukan oleh tim pengabdian kepada masyarakat program studi pendidikan matematika Universitas PGRI Palembang kepada sebagian besar guru SMA Negeri 11 diketahui bahwa aplikasi ini masih merupakan hal yang asing. Guru belum mengenal apa itu Kahoot!, bagaimana cara menggunakannya dan manfaatnya dalam pembelajaran. Hal ini disebabkan karena pembelajaran yang dilangsungkan di sekolah masih secara tatap muka. Sehingga, penggunaan laptop ataupun smartphone terbatas untuk alat administrasi dan komunikasi, belum dimanfaatkan secara maksimal untuk proses pembelajaran. Hal ini juga sejalan dengan pendapat yang dikemukakan oleh Arifin and Hala (2019).

Oleh karena itu, sebagai upaya untuk meningkatkan keterampilan guru dalam menggunakan aplikasi Kahoot! sebagai media dalam pembelajaran, tim pengabdian kepada masyarakat program studi pendidikan matematika Universitas PGRI Palembang tertarik untuk mengadakan pelatihan penggunaan aplikasi Kahoot!. Tema yang diangkat dalam kegiatan pengabdian kepada masyarakat (PKM) ini adalah "Pelatihan Aplikasi Media Pembelajaran Kahoot! di SMA Negeri 11 Palembang". Adapun tujuan kegiatan PKM ini adalah : (1) untuk mengenalkan aplikasi Kahoot! sebagai media pembelajaran khususnya dalam membuat kuis online, (2) untuk meningkatkan keterampilan guru dalam menggunakan aplikasi Kahoot! .

\section{METODE PELAKSANAAN}

Kegiatan PKM ini dilaksanakan di SMA Negeri 11 Palembang dengan alamat J1. Inspektur Marzuki, Siring Agung, Kec. Ilir Bar. I, Kota Palembang, Sumatera Selatan. Kegiatan ini dilangsungkan pada tanggal 25 November 2019. Kegiatan ini diikuti oleh 29 orang guru yang mengajar beberapa mata pelajaran di SMA Negeri 11 Palembang. Sasaran kegiatan PKM ini adalah peningkatan keterampilan guru dalam menggunakan aplikasi Kahoot! sebagai media pembelajaran. Metode pelaksanaan kegiatan ini adalah metode ceramah, diskusi dan praktik. Metode kegiatan PKM dapat dilihat lebih rinci dalam

Tabel 1. Metode Pelaksanaan Kegiatan PKM

\begin{tabular}{ll}
\hline \multicolumn{1}{c}{ Metode } & \multicolumn{1}{c}{ Deskripsi } \\
\hline Ceramah & $\begin{array}{l}\text { Metode ini dilakukan dia wal kegia tan, dan ditujukan untuk menyampaikan materi } \\
\text { terntang aplikasi Kahoot! }\end{array}$ \\
\hline Praktik dan & Peserta kegiatan melakukan praktik da lam membuat kuis online dengan \\
diskusi & menggunakan a plikasi Kahoot!. Praktik inijuga diiringidengan m et ode diskusi \\
& yaitu tanya jawabantara peserta dengan tim instruktur dalam menjalankan aplikasi \\
& Kahoot!.
\end{tabular}


Untuk melihat ketercapaian sasaran kegiatan PKM, peserta diharuskan untuk mengisi angket kepuasan pelaksanaan pelatihan. Selanjutnya, angket dianalisis secara deskriptif kualitatif.

\section{HASIL DAN PEMBAHASAN}

Kegiatan PKM ini dilaksanakan dalam 2
Kahoot! oleh tim PKM Program Studi Pendidikan Matematika Universitas PGRI Palembang, dan sesi kedua adalah praktikum menggunakan aplikasi Kahoot! dalam membuat kuis online. Deskripsi kegiatan dapat dilihat pada Tabel 2 .

sesi, sesi pertama berisi pemaparan materi

Tabel 2. Deskripsi Pelaksanaan Kegiatan PKM

\begin{tabular}{|c|c|c|c|}
\hline No & Waktu & Pemateri & Kegiatan \\
\hline \multirow[t]{3}{*}{1} & $08.00-09.30$ & Dr. Nila kesumawati, M.Si. & Pembukaan \\
\hline & & Putri Fitria sari, M.Pd. & Pemaparan tentang a plikasi Ka hoot! \\
\hline & & & $\begin{array}{l}\text { Penjela san tentang bagaimana meng gu nakan } \\
\text { aplikasi Ka hoot! }\end{array}$ \\
\hline \multirow[t]{5}{*}{2} & $09.30-12.30$ & Tim PKM & $\begin{array}{l}\text { Praktikum membuat kuis online dengan } \\
\text { menggunakanaplikasi Kahoot! }\end{array}$ \\
\hline & & & Diskusi dan tanya jawab tentang kesulitan \\
\hline & & & $\begin{array}{l}\text { yang dinadapi saat menggunakan aplikasi } \\
\text { Kahoot! }\end{array}$ \\
\hline & & & Presentasidanujicoba kuis online yang tela h \\
\hline & & & Penutup \\
\hline
\end{tabular}

Pada sesi pertama, narasumber dengan menjalankan aplikasinya. Contoh materi menjelaskan bagaimana cara yang digunakan yang dipaparkan oleh narasumber dapat dilihat untuk menjalankan aplikasi Kahoot!. Peserta pada Gambar 1. Pelaksanaan pemaparan materi kegiatan PKM dibimbing untuk registrasi dan log dapat dilihat pada Gambar 2. in ke aplikasi Kahoot!. Setelah itu dilanjutkan

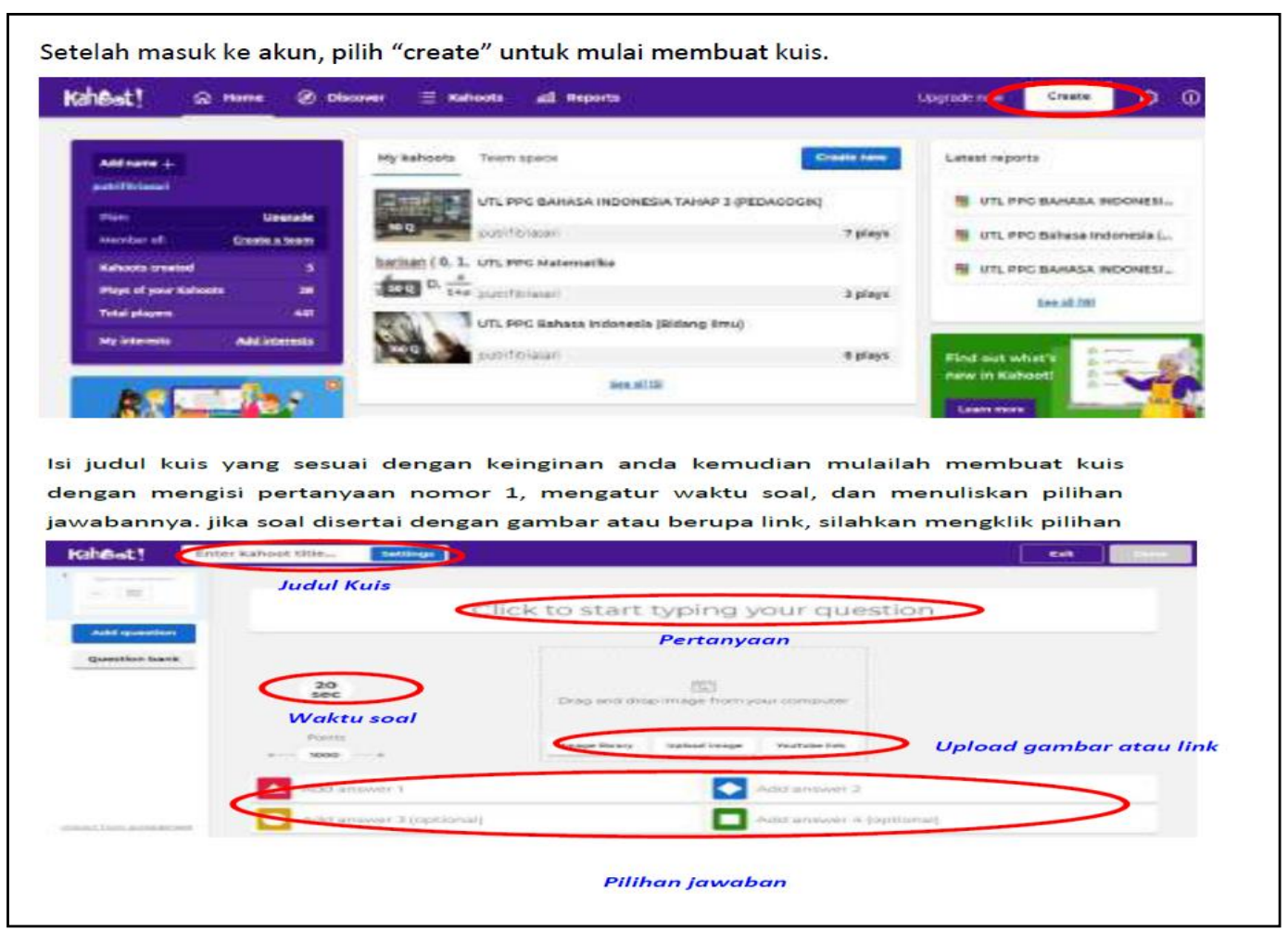

Gambar 1. Contoh materi paparan 


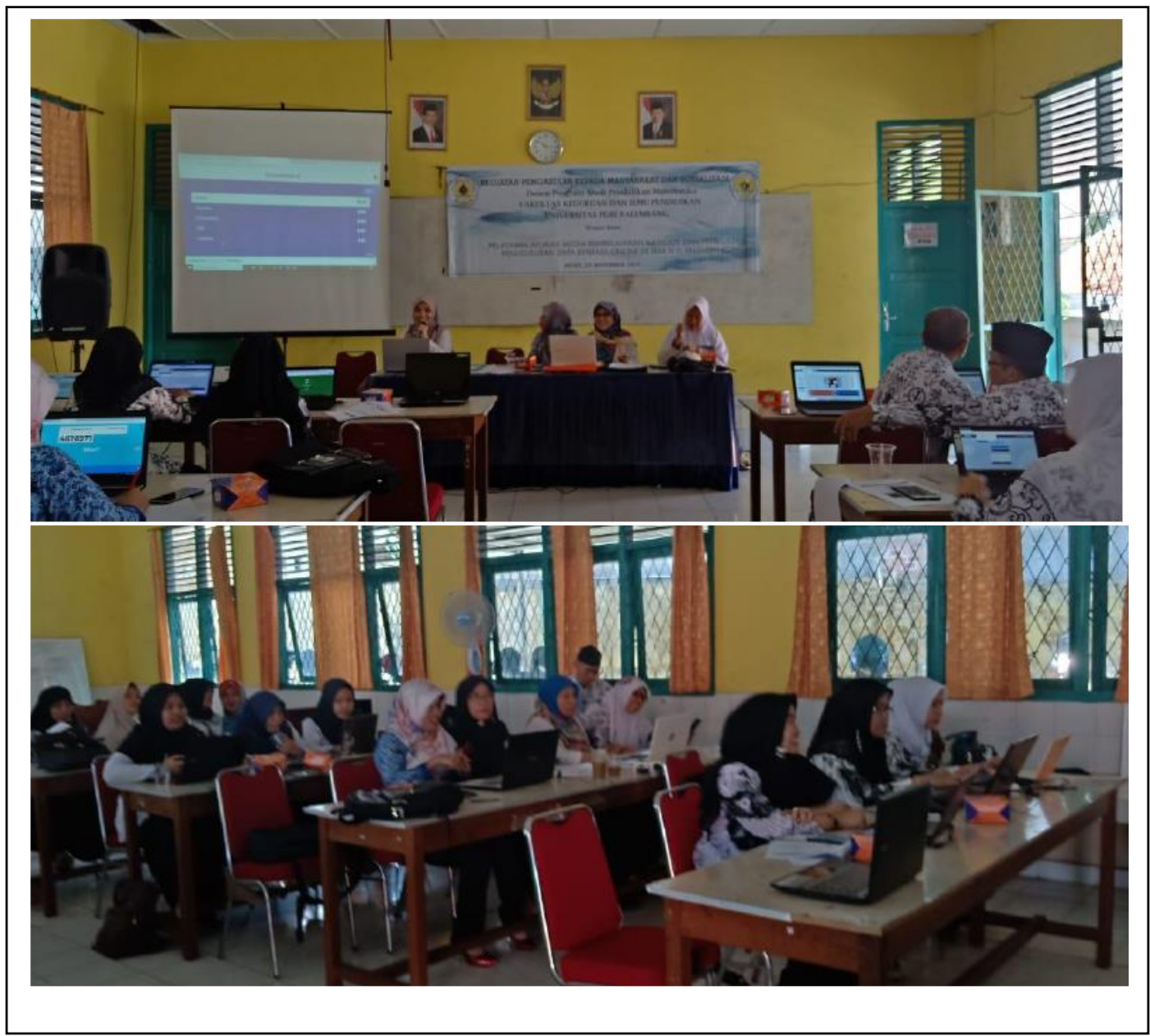

Gambar 2. Pelaksanaan Pemaparan Materi

Pada saat kegiatan pemaparan materi oleh peserta kegiatan PKM. Pada praktikum tim oleh narasumber, peserta menyimak dan PKM memberikan bantuan kepada peserta yang memperhatikan dengan baik. Selanjutnya, mengalami kesulitan. Proses pelaksanaan kegiatan praktikum penggunaan aplikasi Kahoot! praktikum dapat dilihat pada Gambar 3.

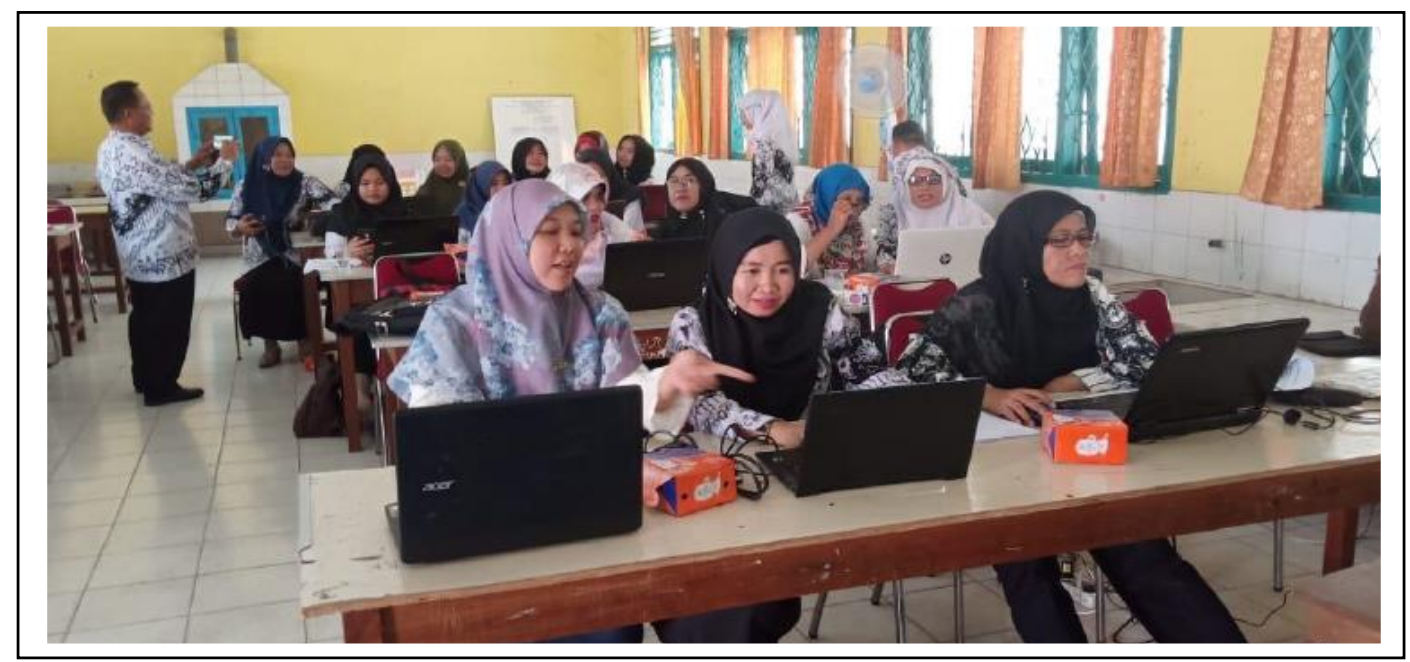

Gambar 3. Praktikum Penggunaan Aplikasi Kahoot!

Setelah melakukan praktik, peserta untuk mengevaluasi pelaksanaan pelatihan. diminta untuk mengisi angket yang ditujukan Angket yang diberikan berupa 8 pernyataan yang 
terkait dengan kegiatan PKM. Hasil angket yang

diperoleh dapat dilihat pada Tabel 3.

Tabel 3. Hasil evaluasi kegiatan PKM

\begin{tabular}{lll}
\hline No & \multicolumn{1}{c}{ Pernyataan } & Persentase \\
\hline 1 & Materipelatihan ini sesuaidengan kebutuhan & 89,66 \\
\hline 2 & Metode pelatihan sesuai dengan jenis pela tihan & 87,07 \\
\hline 3 & Kemampuan instruktur sudah sesuai dengan harapan & 88,80 \\
\hline 4 & Sarana pelatihan sudah efektif & 85,30 \\
\hline 5 & Saya antusias mengikuti pelatihan ini & 87,07 \\
\hline 6 & $\begin{array}{l}\text { Pelatihan ini dapat meningkatkan keterampilan guru dalam } \\
\text { membuat kuis online melalui aplikasi Kahoot! }\end{array}$ & 90,52 \\
\hline 7 & $\begin{array}{l}\text { Pelatihan ini dapat membangkitkan ra sa ingin tahu tentang } \\
\text { pemanfaatan a plikasi Kahoot! dalam pembelajaran }\end{array}$ & 91,38 \\
\hline 8 & $\begin{array}{l}\text { Guru perlu dibekalipelatihan iniagar dapat membuat } \\
\text { pembelajaran menjadi lebih bervariasi }\end{array}$ & 89,66 \\
\hline
\end{tabular}

Berdasarkan Tabel 3 diketahui bahwa peserta kegiatan antusias dalam mengikuti PKM ini, dengan persentase sebesar $87,07 \%$. Kegiatan ini juga berhasil menambah pengetahuan guru tentang penggunaan aplikasi Kahot! dalam pembelajaran, skor yang ditunjukkan pada pernyataan ini adalah sebesar $91,38 \%$. Selain itu dari hasil angket juga diketahui bahwa kegiatan PKM ini dapat meningkatkan keterampilan guru dalam menggunakan aplikasi Kahoot! sebagai alat untuk membuat kuis online.

Sikap antusias dan ketertarikan guru dalam mengikuti pelatihan aplikasi Kahoot! ini juga sesuai dengan pelatihan sejenis yang telah dilaksanakan oleh Arifin \& Hala (2019). Selain itu, kegiatan pelatihan yang menggunakan informasi teknologi dalam pembelajaran mendapat sambutan yang baik dari para guru, hal ini terlihat dari tingkat keaktifan guru yang tinggi (Habinuddin, Sartika, Suryani, Murniati, \& Binarto, 2016).

Proses pelaksanaan kegiatan PKM berjalan dengan lancar dan baik, namun masih terdapat sedikit kendala pada jaringan internet yang tersedia. Sarana pelatihan seperti jaringan internet ini dinilai sebesar $85,30 \%$ oleh para peserta. Sarana yang belum memuaskan ini mendapat skor terendah dari evaluasi kegiatan yang telah dilakukan. Aplikasi Kahoot! bersifat online sehingga guru harus mutlak menyiapkan jaringan internet untuk menggunakannya. Pada saat pelatihan PKM pihak sekolah belum menyediakan titik hotspot yang dapat digunakan secara gratis oleh peserta, selain itu dari pihak Tim PKM sendiri telah menyediakan beberapa modem, namun tidak bisa memenuhi kebutuhan internet peserta pelatihan. Kendala jaringan internet seperti ini juga senada dengan kegiatan yang dilakukan oleh Arifin \& Hala (2019).

\section{SIMPULAN DAN SARAN}

Berdasarkan hasil kegiatan PKM ini dapat ditarik simpulan sebagai berikut : (1) PKM ini bermanfaat dalam mengenalkan aplikasi Kahoot! sebagai media pembelajaran khususnya dalam membuat kuis online, (2) PKM ini dapat meningkatkan teterampilan guru dalam menggunakan aplikasi Kahoot!. Adapun saran yang dapat disampaikan terkait PKM ini adalah agar PKM ini dapat dilakukan pada Sekolah yang lain, khususnya pada daerah di luar kota Palembang.

\section{DAFTAR PUSTAKA}

Arifin, A. N., \& Hala, Y. (2019). Pemanfaatan Kahoot sebagai quiz game interaktif bagi pendidik di Kabupaten Gowa. Seminar Nasional Pengabdian Kepada Masyarakat, 2019(8), 526-529. https://ojs.unm.ac.id/semnaslpm/article/vie w/11666

Chan, B. S. K., Churchill, D., \& Chiu, T. K. F. (2017). Digital literacy learning in higher education through digital storytelling approach. Journal of International Education Research (JIER), 13(1), 1-16.

Heni, V., Sudarsono, S., \& Regina, R. (2017). USING KAHOOT TO INCREASE STUDENTSâ€ $€^{\text {TM }}$ ENGAGEMENT AND ACTIVE LEARNING: A GAME BASED TECHNOLOGY TO SENIOR HIGH 
SCHOOL STUDENT. ICoTE Proceeding s, 2(2), 236-241.

Kurnianingsih, I., Rosini, R., \& Ismayati, N. (2017). Upaya Peningkatan Kemampuan Literasi Digital Bagi Tenaga Perpustakaan Sekolah dan Guru di Wilayah Jakarta Pusat Melalui Pelatihan Literasi Informasi. Jurnal Pengabdian Kepada Masyarakat (Indonesian Journal of Community Engagement).

https://doi.org/10.22146/jpkm.25370

Lankshear, C., \& Knobel, M. (2008). Digital literacies: Concepts, policies and practices (Vol. 30). Peter Lang.

Licorish, S. A., Owen, H. E., Daniel, B., \& George, J. L. (2018). Students' perception of Kahoot!'s influence on teaching and learning. Research and Practice in Technology Enhanced Learning, 13(1), 123.
Putri, A. R., \& Muzakki, M. A. (2019). Implemetasi Kahoot Sebagai Media Pembelajaran Berbasis Digital Game Based Learning Dalam Mengahadapi Era Revolusi Industri 4.0. Prosiding Seminar Nasional Universitas Muria Kudus, 1-7.

Wang, A. I., \& Tahir, R. (2020). The effect of using Kahoot! for learning-A literature review. Computers \& Education, 149, 103818.

Wibisono, D. (2019). The effects of Kahoot! In teaching reading to tenth grade students. Magister Scientiae, 1(45), 86-105. 